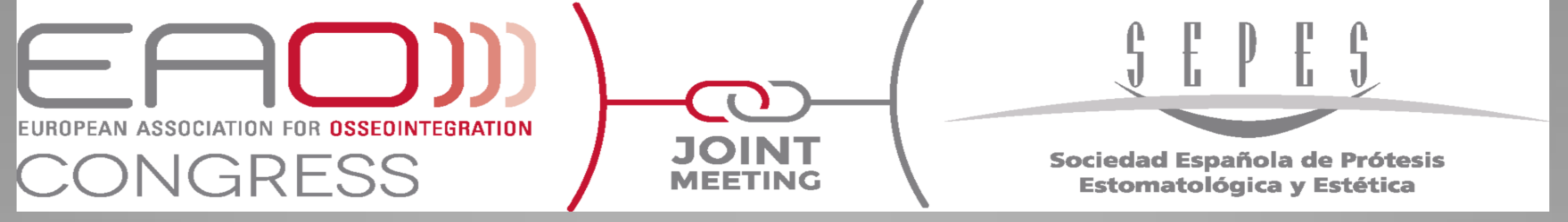

\title{
Evaluation of implant stability assessed by Osstell Mentor in grafted and nongrafted sinus lift procedures
}

Denis Baftijari, 1 University Clinic for Maxillofacial Surgery - Skopje Macedonia,

Alberto Benedetti, 2University Clinic for Maxillofacial Surgery - Skopje Macedonia,

Darko Veljanovski,- 3Private dental practice Optimuim Dental - Skopje Macedonia,

Florent Baftijari, 4University Clinic for Prosthodontics - Skopje Macedonia

Vanco Spirov,- 5University Clinic for Oral Surgery - Skopje Macedonia

Clinical studies have shown that posterior maxilla is associated with challenges in the implant dentistry. Sinus lift procedures are required for sufficient bone volume in the maxillary ridge. Osseointegration of titanium implants in and their stability in grafted and nongrafted sites has been shown by means of resonance frequency analysis (RFA).

Aim: The aim of our study was to evaluate the implant stability quotient (ISQ) results of the resonance frequency (RF) in grafted and nongrafted sinus lift procedures on the first day of surgery and after 1, 4, 16 weeks of healing period.

Material and methods: In this study were included 58 healthy patients, where sinus lift was obtained. In all, 137 SLA ITI Standard plus implants were placed.

In the first group of 27 patients, 62 implants were placed following sinus lift and grafted with Bio Oss $0.25-1 \mathrm{~mm}$ particle size (small particles), and in the second group of 31 patien ts 75 implants were placed without bone augmentation. Resonance frequency analysis (RFA) was measured at both groups to get implant stability quotient (ISQ) values. Student's t test was used to calculate $P$ values for ISQ with Statistica 7.

Results: On the first day and one week after surgery no statistical difference was observed in ISQ values of implants placed in grafted and nongrafted sinus lift procedures $(p=0,651)$. After 4 and 16 weeks, grafted sites showed higher ISQ values than the control site.

Conclusion: Sinus lift procedures on grafted sites offer better long term stability. RFA values during the healing period are predictable for the implant outcome during maxillary sinus lift procedures.

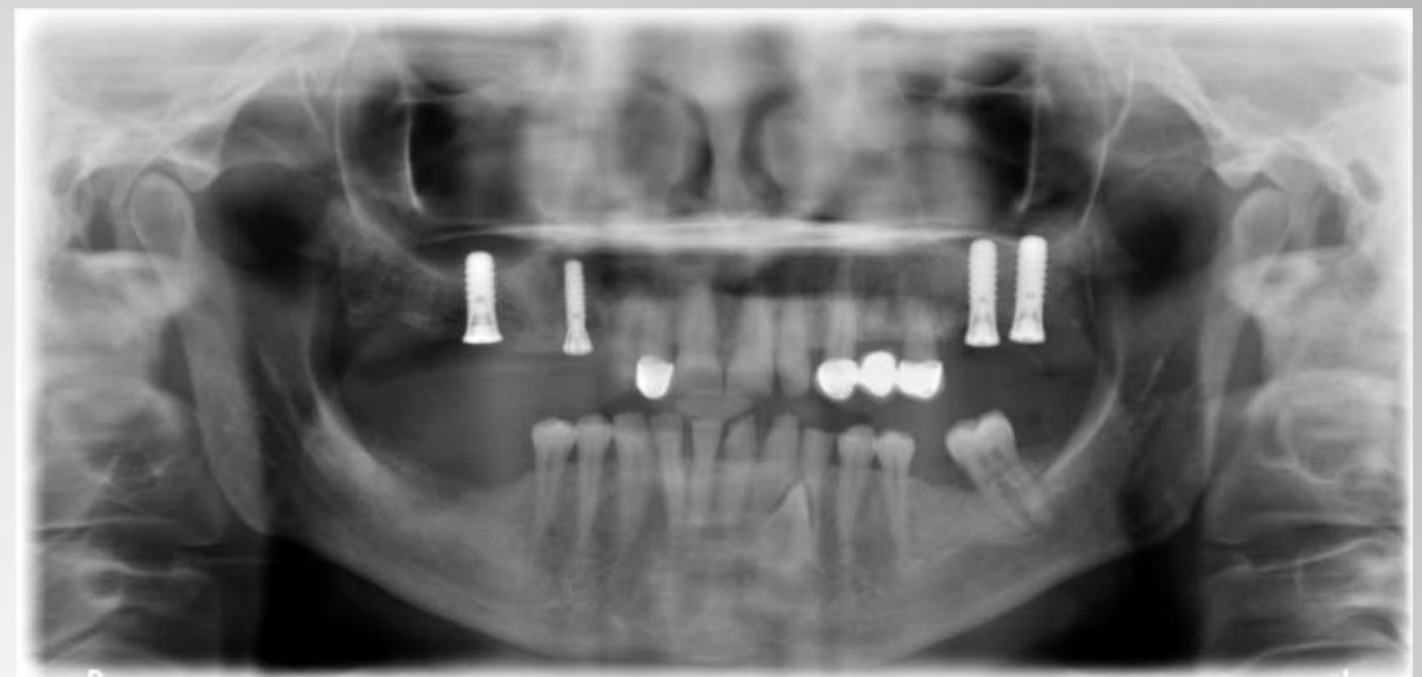

Pic. 1. OPG of left side without bone graft and right side with bone grafting

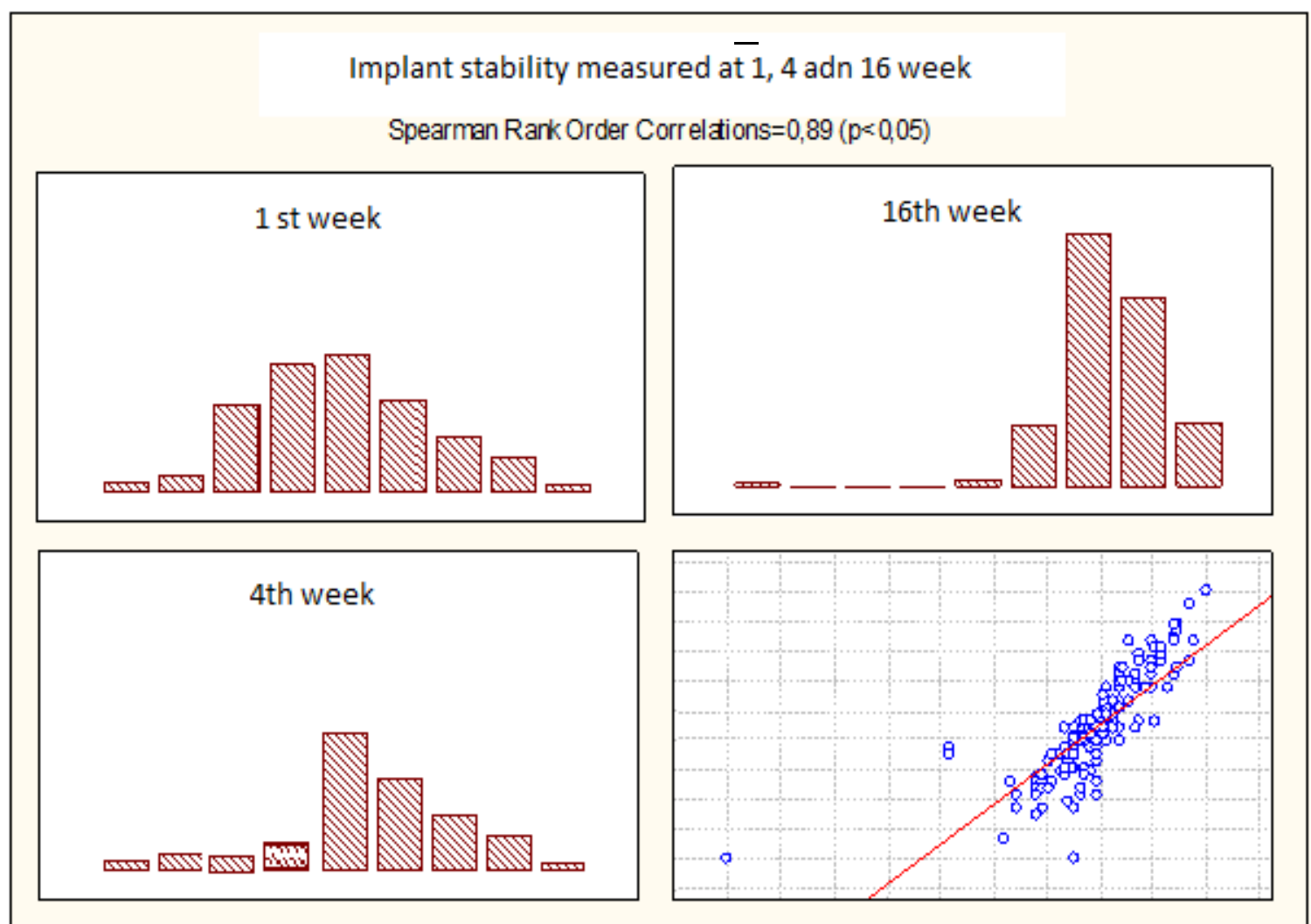

Graphicon.1. Difference between implant stability at 1, 4 and 16 week

\begin{tabular}{|c|c|c|c|c|c|c|c|c|}
\hline $\begin{array}{c}\text { Secondary } \\
\text { stability } \\
16^{\text {th }} \text { week }\end{array}$ & Mean ISQ & Std.Dv. & $\mathrm{N}$ & Diff. & $\begin{array}{c}\text { Std.Dv. } \\
\text { Diff. }\end{array}$ & $\mathrm{t}$ & $\mathrm{df}$ & $\mathrm{p}$ \\
\hline $\begin{array}{c}\text { With } \\
\text { grafting }\end{array}$ & 69,18 & 6,59 & 62 & & & & & \\
\hline $\begin{array}{c}\text { Without } \\
\text { grafting }\end{array}$ & 58,08 & 6,31 & 75 & $-7,90$ & 4,21 & $-15,70$ & 69 & 0,000 \\
\hline
\end{tabular}

Tabl.1. Secondary stability at 16 th week after surgery

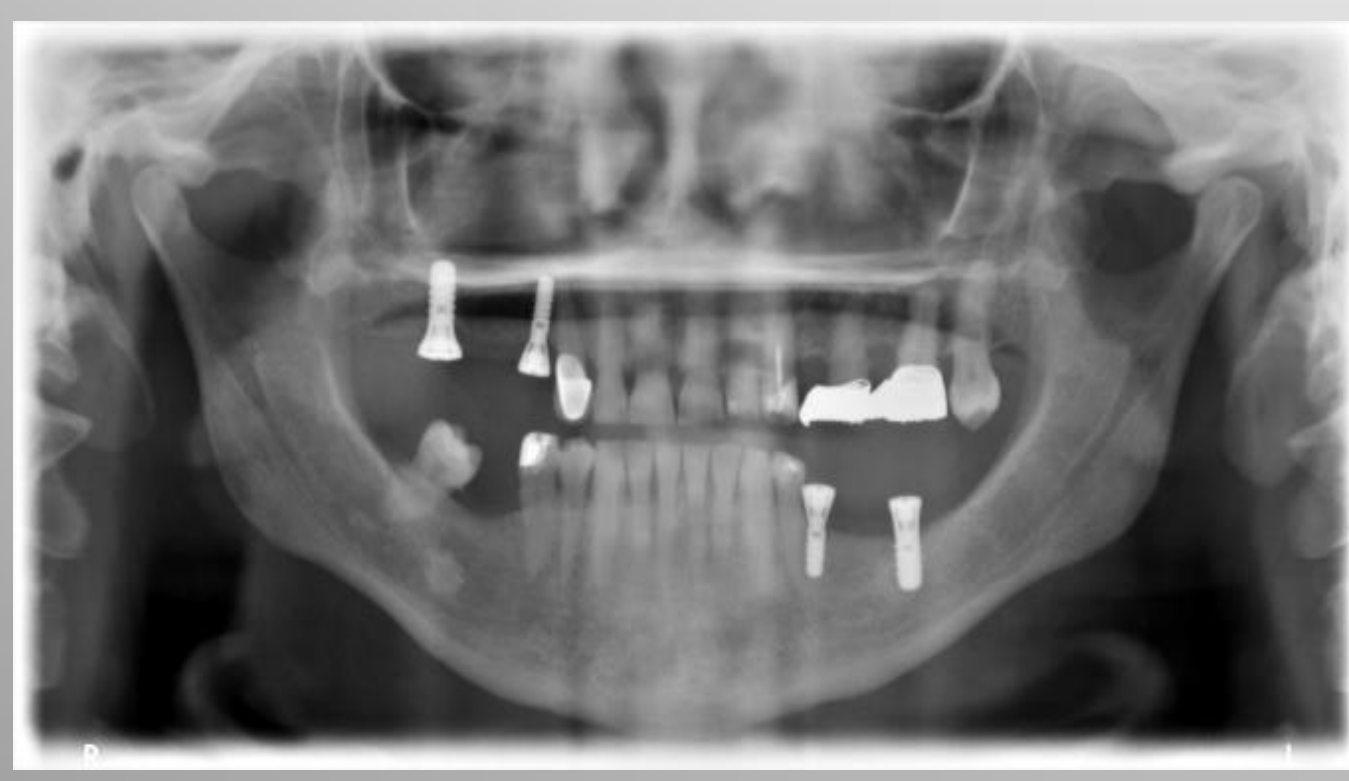

Pic. 2. OPG with bone grafting after period of osteointegration

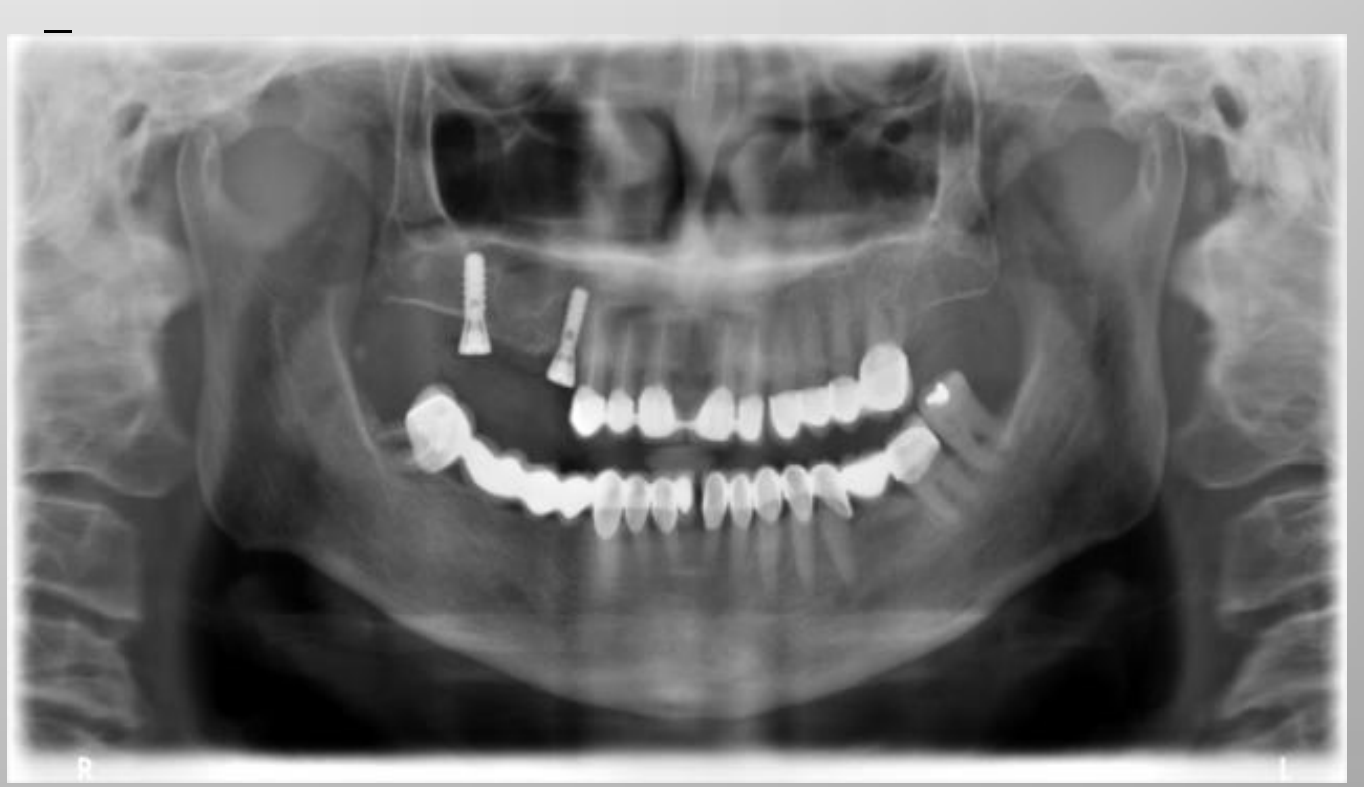

Pic.3. Opg without bone grafting after the period of osteointegration 